\title{
STEM Integration for High School Mathematics Teachers
}

\author{
Micah Stohlmann iD \\ University of Nevada, USA
}

\begin{abstract}
The discipline of mathematics in science, technology, engineering, and mathematics (STEM) integration has not yet been consistently connected in a clear way for a large amount of high school mathematics teacher to implement STEM integration well. In response to this I have proposed a focus on integrated steM education; the integration of STEM subjects with an explicit focus on mathematics. There are benefits to integrated steM education in a mathematics classroom including increased motivation, interest, and achievement for students. Integrated steM integration can also prepare students with the needed proficiencies and knowledge bases to be productive and impactful members of society. This article discusses three methods that high school mathematics teachers can utilize for integrated steM education. By focusing on open-ended problems through engineering design challenges, mathematical modeling, and mathematics integrated with technology high school students are more likely to see mathematics as meaningful and valuable. Examples of each method are discussed along with common instructional elements among the methods.
\end{abstract}

Keywords: High School Mathematics Teachers, STEM Integration

\section{Introduction}

The technologically based data driven world in which we live in has made science, technology, engineering, and mathematics (STEM) education and STEM careers of great importance. In everyday life and careers people often solve problems that require knowledge from multiple subjects. Too often though in school, the STEM disciplines are taught within silos independent of each other and when integration has occurred mathematics has often had a diminished role (English, 2016; Fitzallen, 2015; Shaughnessy, 2013). In prior STEM integration research it seems that mathematics learning benefits less than the other disciplines (English, 2016). This necessitates the need for future research and discussion on how mathematics can receive focus in well-designed STEM integration curricula. Along these lines I have researched and proposed more work done with integrated steM education. I use the acronym steM to mean integrated STEM education that has an explicit focus on mathematics (Stohlmann, 2018). High school mathematics teachers can implement integrated steM education through open-ended problems in three main ways: engineering design challenges, mathematical modeling, and mathematics integrated with technology through game-based learning (Stohlmann, 2019a). In recent years it was found that $45 \%$ of STEM jobs were connected to computers, and engineering jobs made up an additional 19\% of the STEM workforce (Fayer, Lacey, \& Watson, 2017). In addition mathematical modeling often has connections to technology and engineering (Zawojewski, Hjalmarson, Bowman, \& Lesh, 2008). If high school mathematics teachers implement integrated steM education it can not only develop mathematical understanding and interest in mathematics, but also expose students to possible careers in STEM fields with job availabilities.

Corresponding author: University of Nevada, Las Vegas 4505 S. Maryland Parkway \#453005 Las Vegas, NV 89154, Email: micah.stohlmann@unlv.edu Stohlmann, M. (2020). STEM integration for high school mathematics teachers. Journal of Research in STEM Education, 6(1), 52-63. 
In the United States, there is currently a shortage of STEM majors and graduates (National Science Board, 2015). These shortages of STEM education qualified workers include the fields of engineering, computer science, web and app developers, cybersecurity, and manufacturing jobs (Maiorca, Stohlmann, \& Driessen, 2019). In order to fill the pipeline of STEM professionals it is important that students are properly prepared to have the opportunity to pursue aSTEM career if they desire. Research has shown that students who perform well in calculus, pre-calculus, trigonometry, physics, and chemistry in high school are more likely to be successful in college STEM gatekeeper courses (Redmond- Sanogo, Angle, \& Davis, 2016). These gatekeeper courses can be STEM content courses that students are not able to be successful in and hinder them from completing a STEM degree. There is work to do at the high school level to ensure that students are prepared for college level STEM courses. Only $26 \%$ of students who indicated an interest in STEM majors or careers met or surpassed the ACT College Readiness Benchmark in STEM (ACT, 2017). An integrated steM education approach has the potential to keep more students engaged in mathematics at the high school level to be better prepared for college-level mathematics.

As society becomes increasingly more dependent on STEM knowledge it is vital for those who do not plan on pursuing a career in a STEM field to receive integrated STEM education instruction as well (Surr, Loney, Goldston, Rasmussen, \& Anderson, 2016). An authentic integrated STEM learning experience is important for all students because it encourages students to use teamwork and problem solving; skills they need to be successful in life regardless of their chosen profession (National Academy of Science, 2014). Whether students end up in a STEM career or not, learning through an integrated steM education approach will benefit students. I will now provide more detail on integrated steM education and then discuss the three main methods for high school mathematics teachers.

\section{Definition of Integrated steM}

Integrated steM education is an effort to combine mathematics with at least one other STEM discipline into a unit or lesson that is based on connections between the subjects and socially relevant problems. It involves a focus on grade level mathematics through content integration while being supported and enhanced by science, technology, and/or engineering (Stohlmann, 2019a). This is important because in the past mathematics teachers have noticed that integrated STEM lessons do not always align with grade-level mathematics content standards (Lesseig et al., 2016). There are not specific combinations of STEM subjects that are inherently better than others. The subjects that are integrated should depend on the natural connections between the subjects that are aided by the realworld contexts. Further, integrated steM education is an approach that builds on natural connections between STEM subjects for the purpose of (a) developing student understanding of each discipline by building on students' prior knowledge; (b) broadening student understanding of each discipline through exposure to socially relevant STEM contexts; and (c) making STEM disciplines and careers more accessible and intriguing for students (Wang, Moore, Roehrig, \& Park, 2011).

There are varying levels of integration of STEM concepts. Table 1 provides four different levels described by Vasquez, Sneider, \& Comer (2013). The goal for integrated steM education for high school mathematics teachers is to be at the Transdisciplinary level by drawing either on their own knowledge bases, their students' knowledge from other STEM classes, or the knowledge of other STEM disciplinary teachers at a school. STEM content knowledge is certainly a concern for implementation but the idea that integrated steM education can be implemented into mathematics classes once or twice a chapter will make it more likely for gradual implementation that can be successful. 
Table 1

Levels of integration

Forms of integration

1. Disciplinary

2. Multidisciplinary

3. Interdisciplinary

4. Transdisciplinary

\section{Features}

Concepts and skills are learned separately in each discipline.

Concepts and skills are learned separately in each discipline but within a common theme.

Closely linked concepts and skills are learned from two or more disciplines with the aim of deepening knowledge and skills.

Knowledge and skills learned from two or more disciplines are applied to real-world problems and/or projects.

Within the levels of integration there are different approaches that high school mathematics teachers can use for integrated steM education including team planning and individual implementation (Roehrig, Moore, Wang, and Park, 2012). Team planning is where a group of teachers might plan a lesson or unit together and then implement this in their own classroom. This team planning would be more likely to occur within STEM subjects; for example, a team of mathematics teachers meeting together to plan, but could also involve seeking feedback from teachers outside of a team's subject area. Another structure, individual planning and implementation, involves one teacher working by him or herself to implement integrated STEM which could involve seeking advice from teachers in other disciplines. This paper will focus on what high school mathematics teachers can accomplish using the team planning or individual implementation structure of steM integration. These are the structures that are most likely to be able to implemented by high school mathematics teachers due to time, planning, and topic sequencing restrictions.

There are three main ways that high school mathematics teachers can implement integrated steM in their classroom. This can be done by focusing on open-ended problems through engineering design challenges, mathematical modeling, and mathematics integrated with technology. The three modes of integrated steM make implementation more likely because each mode implements mathematics with a different STE subject so teachers can begin with integration they are more comfortable with. Each of the three modes will now be discussed.

\section{Integrated steM Through Engineering Design}

When students get to high school, it is becoming more likely that they have had experiences with engineering design. In the U.S., twenty states have adopted the Next Generation Science Standards (NGSS, 2013), which include engineering design at the elementary, middle, and high school levels. There are several additional states that also include engineering design in their science standards (Carr, Bennett, \& Strobel, 2012). Even if students have not had engineering design experience by the time they enter high school, the types of activities that high school mathematics teachers can use, Model-Eliciting Activities (MEAs), have a strong research and practice tradition in mathematics education.

MEAs are student-centered, open-ended, team-based, realistic problems that enable students to solve complex problems (Lesh \& Doerr, 2003). MEAs were designed explicitly to focus on mathematical knowledge and competencies that are needed for success beyond school. There are many more complex systems in the world and the people that can make sense of these systems will be more successful (Lesh and Doerr, 2003). The engineering design process is incorporated in the activities as students express, test, and revise their ideas (English, 2010). MEAs enable students to see that most engineering problems do not have a single, correct solution, and highlight how engineering is a creative endeavor. MEAs can be used as a formative assessment or as a way for students to apply the mathematics they have learned in previous lessons.

The general format of MEAs involves students reading an article or watching a video to provide background information on the problem that will be solved. Then students answer a few 
readiness questions and there is a whole-class discussion. Students then have time to work on the problem. The teacher can monitor students working and then select and sequence groups that will share. The format of MEAs and integrated steM education in general ties in nicely with the 5 practices for orchestrating productive discussion (Smith, Hughes, Engle, \& Stein, 2009) for how teachers can implement these lessons.

1. Anticipating likely student responses to challenging mathematical tasks;

2. monitoring students' actual responses to the tasks (while students work on the tasks in pairs or small groups);

3. selecting particular students to present their mathematical work during the whole-class discussion;

4. sequencing the student responses that will be displayed in a specific order; and

5. connecting different students' responses and connecting the responses to key mathematical ideas (Smith \& Stein, 2008, p.11).

The rocket MEA (Maiorca, 2016) is an example of an MEA that could be implemented as way for students to apply understanding of trigonometric ratios in right triangles. The background article talks about how commercial spaceflight has been receiving more attention. The problem statement asks students to design a rocket that will go the highest. The context is that the rocket could be used to provide supplies to the international space station.

Before students begin designing their 2-liter bottle rocket, they use a 2-liter bottle rocket launch simulator to begin to develop their ideas. In the simulator students conduct multiple tests of a rocket by changing cone style, nose weight, body weight, tail weight, the amount of water in the rocket, and pressure. The simulator provides the altitude, velocity, and time in flight of the rocket (Figure 1).
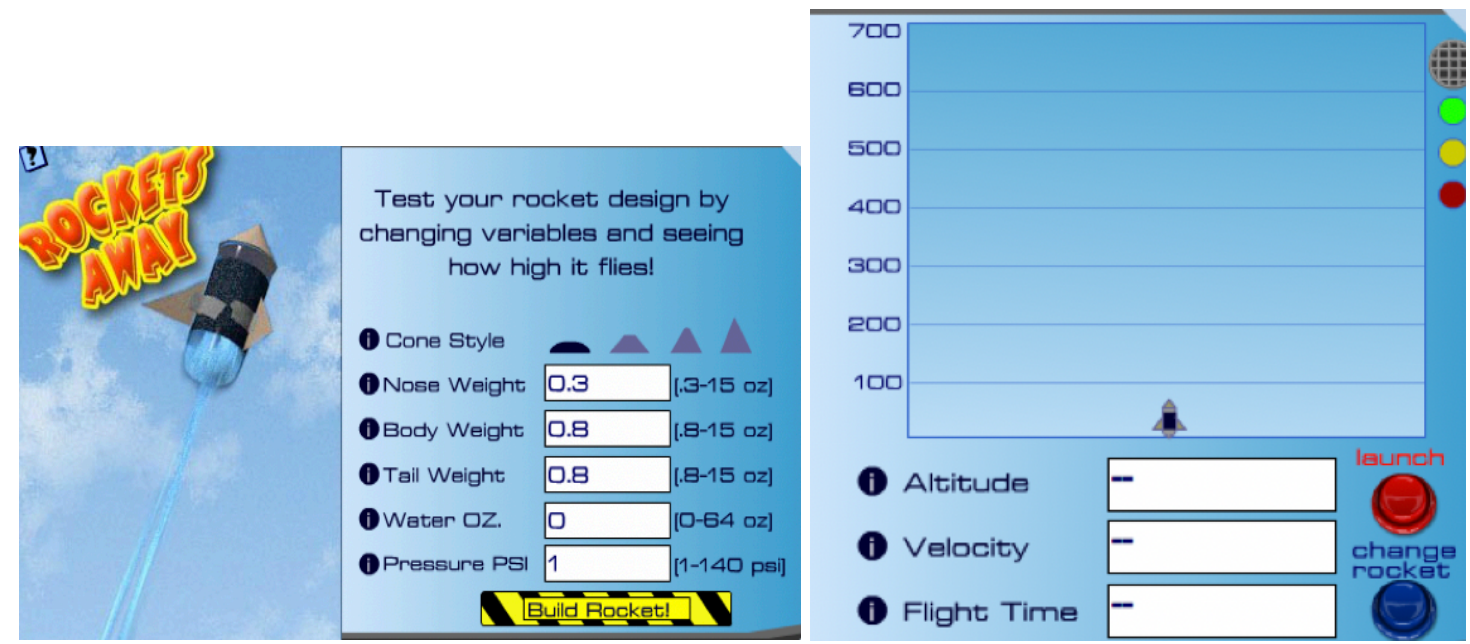

Figure 1. Rocket simulator (Ohio4H, 2017)

Around 640 feet is the highest the rocket can fly. This is accomplished with the following conditions: cone style (4th option), nose weight $(8 \mathrm{oz})$, body weight $(0.8 \mathrm{oz})$, tail weight $(0.8 \mathrm{oz})$, water $(30 \mathrm{oz})$, and pressure (140 psi). The cone that is closest to a triangle is the most aerodynamic of the choices. For the cone weight, too much can decrease height but too little would cause the rocket to spin over the top. Less is better for the body and tail weights. Since force equals mass times acceleration the goal is to push out the most mass (water and air) in the shortest amount of time. Too much water, and the air pressure is not strong enough to push it out fast enough. Too little water and the mass that is expelled is smaller which decreases the force. The simulator provides a good opportunity to have discussion with students with connections to force and Newton's laws of motion. 
Students are then given materials they can use including 2-liter soda bottles, tennis balls, foam floral cones, Styrofoam, cardstock, and duct tape to build their rocket. Before students test their rockets, it can be discussed how the height will be estimated. Students can be provided a diagram of the situation to see if they can see how the height could be estimated (Figure 2). Once students have recognized that tangent can be used to determine the height, it can be shown how the angle will be measured. A clinometer can be used by attaching a straw to a protractor and then tying a piece of string that can hang down with a weight attached.

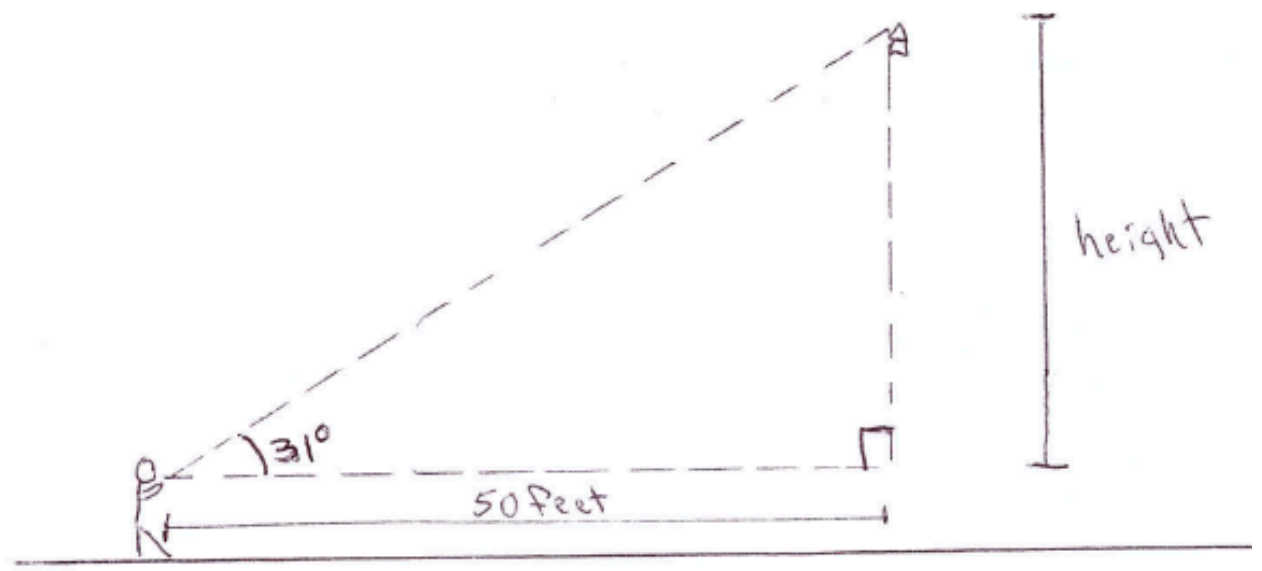

Figure 2. Right triangle diagram

A GeoGebra app can be used to have students see how the clinometer will work (Figure 3). In implementing this activity with students I have found that this is an important part as students may record the incorrect angle. The angle that students should use is the compliment of the acute angle. Through this MEA, students are able to apply their mathematical knowledge through an engaging design challenge.

\section{GesGebra}

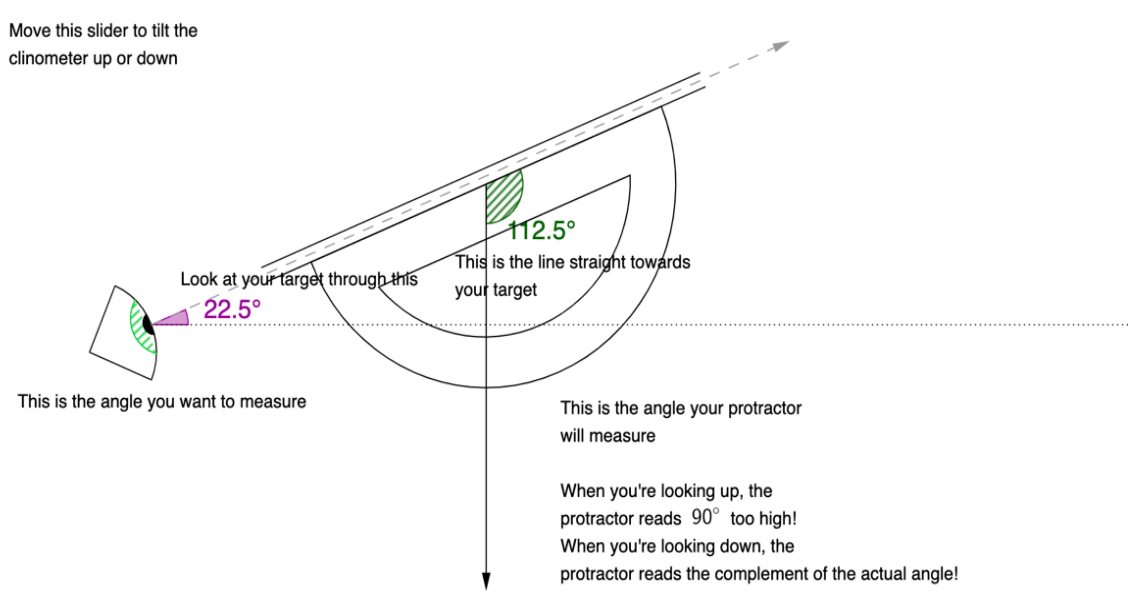

This plumbob measures your angle on the protractor.

Figure 3. Clinometer GeoGebra applet (Sdickson, 2019)

Another example of engineering design with a mathematics focus done at the high school level is for students to design and test catapults. A study done with twenty students that used surveys found that students were highly engaged and became more interested in STEM careers after participating in integrated steM lessons (John, Bettye, Ezra, \& Robert, 2016). Similarly, Bray and 
Tangney (2016) reported students had increased engagement in mathematics after participating in several integrated steM lessons including catapult design.

\section{Integrated steM Through Mathematical Modeling with Science Contexts}

Mathematical modeling is garnering national and international focus due to the many benefits that it can provide to students including increased engagement, understanding through multiple representations, and discourse (Stohlmann \& Albarracin, 2016). Mathematical modeling is one of the Standards for Mathematical Practice in the U.S. Common Core State Standards for Mathematics (National Governors Association, 2010). Additionally, sixteen content standards are highlighted as modeling standards at the high school level. My definition of mathematical modeling is that "mathematical modeling is an iterative process that involves open-ended, real world, practical problems that students make sense of with mathematics using assumptions, approximations, and multiple representations" (Stohlmann \& Albarracin, 2016, p.2). This definition is aligned with the description of mathematical modeling in the Common Core State Standards for Mathematics (CCSSM). Mathematical modeling is becoming more common in high school mathematics and implementing mathematical modeling in science contexts enables high school mathematics teachers to implement integrated steM education. I will describe two example activities that I have implemented with teachers and students that integrates mathematical content standards that are highlighted as modeling standards in the CCSSM.

The first activity is connected to health science and an event held in Las Vegas sponsored by the American Lung Association, whose mission is to save lives by improving lung health. Each year at the Stratosphere Tower people climb up 108 floors of the tower consisting of 1,455 stairs to raise money for the American Lung Association. Shaun Stephens-Wale has the fastest time running up the stairs in 7 minutes and 3 seconds. At the start of this problem a video is shown about the event. The question is then posed if Stephens-Wale would beat someone in an elevator to the top of the tower. Students realized that someone in an elevator should arrive at the top first.

The question for the problem is then posed. How many floors would someone in an elevator have to be stopped at in order to tie Stephens-Wale running up the stairs? (Stohlmann, 2019b). This problem is connected to creating equations that describe numbers or relationships. In figuring out this problem students make different assumptions and approximations including if the elevator is being used by guests of the casino or staff, the speed of the elevator, and the time it takes for people to get on or off the elevator at each stop. Students have also used the Internet to help develop their solution. An example solution involves making an assumption that the elevator takes 1.5 seconds to go up each floor and approximately 17 seconds of wait time for each floor it stops at. This takes into account people getting on and off the elevator. The equation would be the following then: $423=$ $108(1.5)+17 x$ which when solved gives about 15 floors with stops. In this activity the importance of choices and assumptions are highlighted for mathematical modeling.

A second example mathematical modeling activity is connected to physics and is based on a video of a basketball being dropped off the top of the Cotter Ranch Tower building in Oklahoma City (Dude Perfect, 2016). Students are asked to figure out how long it will take the basketball to reach the basketball hoop, which is at the bottom of the building. Students apply their knowledge of quadratics and use an equation and/or graph to determine a solution. $y=-16 t^{\wedge} 2+h$

After students come up with their solution, the video is then watched to see the real answer. It is then found that the actual time is longer than was predicted. Students are asked to explain why this was the case. There are several short YouTube videos that can be integrated into the discussion after students have shared their ideas, which focus on information related to dropped objects (Stohlmann, 2019b). In brief, the basketball takes longer than predicted to reach the basketball hoop because of air resistance. Students may think that if you drop two similar shaped objects from the same height that they will hit the ground at the same time, but this is not always the case. Mathematical modeling in science contexts can engage students in interesting problems. These problems provide the opportunity for rich discourse and for students to draw on knowledge from multiple disciplines. 
Research studies have shown the benefits of this approach with high school students with different science contexts. MEAs and follow-up activities related to light intensity and decay rate of a fully charged capacitor helped students develop their reasoning about average rate of change (Arleback, Doerr, \& O'Neil, 2013). In another study, students were motivated by the context of looking at global oil consumption and predicting when oil reserves may run out (Busse \& Kaiser, 2003). High school students in Australia demonstrated higher order thinking with the ability to apply mathematical knowledge in the context of analyzing animal populations (Brown \& Edwards, 2011). The mathematical content of functions, data analysis, and creating equations have quality connections with mathematical modeling at the high school level. Mathematics teachers can integrate mathematical modeling with science contexts to help students see the many areas that mathematics can be applied.

\section{Integrated steM Through Mathematics Integrated with Technology}

In this section I refer to integrated steM education integrated with technology in regards to open-ended game based learning. Game-based learning has drawn international interest and has been suggested as an effective educational method that can improve students' motivation and performance in mathematics (Byun \& Joung, 2018; Foster \& Shah, 2015; Wang, Chang, Hwang, \& Chen, 2018). Students often play technology-based games whether it is video games or apps on their phones. However, when used in the mathematics classroom, game-based learning is often not implemented in the most effective way. For example, most of the games used in prior research in mathematics classrooms involved drill and practice (Byun \& Joung, 2018).

My definition of integrated steMeducation through game-based learning has several important features that help ensure quality implementation. First, the technology integration should allow for the creation of new tasks that would not be possible without the technology or for significant task redesign (Puentedura, 2006). Second, the tasks used should be worthwhile tasks. These tasks have no prescribed rules or methods and there is no perception that there is a specific "correct" solution method (Hiebert et al., 1997). Third, the tasks should be aligned with grade-level standards. Fourth, the tasks should enable students to work with multiple representations. Fifth, the technology should provide students feedback. Finally, the tasks should be open-ended and allow for discussion and multiple solutions (Stohlmann, 2019c). When structured well, technology-based mathematics games can engage students in mathematics and help develop their conceptual understanding.

One example of game-based learning that high school mathematics teachers can implement is through the use of programming and robotics. There is a movement for states to require computer science courses for students in high school (Computer Science Teachers Association, 2018). As students' knowledge of computer science increases the potential for mathematics teachers to integrate programming and game-based learning also increases. Current technologies for programming are becoming more user-friendly as well, which can make it more likely for mathematics teachers to feel comfortable integrating programming. Exposing students to this work is essential as applications software developers is the largest STEM occupation (Fayer et al., 2017). There is a need for more qualified workers in this area.

Kim and Tjoe (2019) describe how mathematics can be integrated with game-based learning, programming, and robotics. They used the Sphero SPRK+ robotic ball that can be programmed through the Sphero Edu app. The app is user-friendly and compatible with various operating systems and devices. Programming can be done through simply drawing and driving, block-based coding, and JavaScript text programming. The heading, the speed, and the duration can be programmed with the app.

Students programmed the robotic ball with different speeds to travel in a straight line for three seconds and measured the distance traveled. They recorded this information in a table and then worked to come up with a method to predict the distance traveled given a speed. Various ideas were used by groups including proportional reasoning and a line of best fit or linear regression. Students were able to make connections between tables, graphs, equations, and the situation in which the data was collected. The students considered friction between the ball and the floor for 
why the ball might not have traveled as far as they initially thought.

Along with this task, various games can be incorporated with the robotic balls in which students can use their knowledge from the previous task. A track can be setup and students can program the balls to race each other around the track. Mini golf holes can be drawn on paper or setup with blocks and students can program the balls to end up in the hole. Bowling pins can also be setup as another game to be incorporated with the programming.

Another example of technology game-based learning that is open-ended is through the use of Desmos activities. Desmos is an online graphing calculator, but also has a suite of free classroom activities available with some of the activities being game-based. Little research has been conducted on these activities, but they have the potential to enable teachers to develop students' conceptual understanding through multiple representations.

In my research, I did two studies with middle school students using Desmos in teaching experiments (English, 2003). Theses Desmos game-based activities would be appropriate for high school students as well. In the studies I collected the student work in Desmos, audio recordings, and researcher field notes. In the first study I investigated the use of the Desmos online graphing calculator for students to play the game Battleship. Students used linear equation with restricted domains or ranges for the ships and they used equations of circles to take turns seeing if they could hit their opponents' ships. Students cannot see where their opponent had placed the ships and needed to decide where to place the circles to try to hit the ships. Students were actively engaged in the game, and the activity assisted students in making connections between representations of linear equations and circles (Stohlmann, 2017a).

Another example of game-based learning in Desmos is the activity Polygraph lines. I analyzed the data in this study with an interpretative approach by looking at the ways in which students used mathematical vocabulary in the game. In this game, sixteen linear graphs are given. One student selects one of the graphs and the other student asked yes or no questions to determine which graph had been selected. After playing the game several times, the students discussed what are quality questions to ask and strategies for asking the least amount of questions. Through playing the game and subsequent discussions, students were able to make use of mathematical vocabulary including slope, positive slope, negative slope, horizontal line, vertical lines, origin, and quadrants (Stohlmann, 2019a).

\section{Discussion}

In this article I have described three main ways that high school mathematics teachers can implement integrated steM education through open-ended problems: engineering design challenges, mathematical modeling with science contexts, and mathematics integrated with technology through game-based learning. The goal of implementing these methods is to prepare students for the demands of the 21st century with 21st century competencies, while also addressing future workforce needs. Students can be engaged to learn mathematics and increase their understanding through integrated steM education. In general, STEM education disciplines need to have more of a focus on integration (English, 2016). Also, mathematics integration has not received adequate focus in STEM education and future research is needed on how to best support mathematics teachers for this approach (Stohlmann, 2019a; English, 2016; Shaughnessy, 2013). When teachers have received professional development for integrating STEM subjects they grow more confident in their implementation and are more willing to continue integrating STEM subjects (Mayes et al., 2017).

Table 2 provides a summary of important instructional elements for integrated steM education. A focus on student-centered pedagogies, multiple representations, integration of STEM subjects, and open-ended problems can engage students and possibly lead to interest in a STEM career. With these elements, students are more willing to share and discuss their mathematical thinking and learn from each other (Stohlmann, 2017b). The Next Generation Science Standards (NGSS, 2013) at the high school level provide quality connections for integrated steM education. Matter and its interactions, motion, forces, ecosystems and animal populations, and natural resources provide 
good opportunities for high school mathematics teachers to make learning more connected and to integrate science knowledge into mathematics. When mathematics is learned through relevant contexts students can be engaged to continue to put forth effort in learning mathematics. This can lead to possible STEM careers and doing well in college level mathematics classes. High school mathematics teachers can also implement integrated steM education to further show the benefit of mathematical understanding through multiple representations.

Table 2

Instructional elements for integrated steM and future research

Instructional elements for integrated steM curricula

- Open-ended (multiple solutions and tasks are worthwhile tasks (Hiebert et al., 1997).

- Integrated assessment (Assessment is not merely summative but is woven seamlessly into the tasks with students receiving feedback from the technology, other students, the Internet, and the teacher).

- Transdisciplinary perspective (Students make use of knowledge bases from multiple disciplines).

- Collaboration (Students work in teams with the goal of clear communication).

- Real world or social relevance based on students' interest or popular culture.

- Grade level mathematics integrated.

- Multiple representations incorporated.

- 5 practices of orchestrating productive mathematical discussion are implemented (Smith \& Stein, 2011).

\section{Future research}

- Further development of integrated steM curricula.

- Further research on the impact of integrated steM approaches on high school students' mathematical achievement, development of mathematical understanding, mindsets, motivation, and interest in STEM careers.

- Further research on what support teachers need to implement more student-centered learning through integrated steM.

A great benefit of an integrated steM education approach is that teachers will be implementing best practices for teaching mathematics. This can challenge teachers to build on students' ideas and prior knowledge to have a more student-centered approach (Stohlmann, Moore, \& Roehrig, 2012). Effective mathematics teaching practices detailed by the National Council of Teachers of Mathematics (NCTM, 2014) are aligned with an integrated steM education approach. NCTM describes the vision of these practices in that,

"students are active learners, constructing their knowledge of mathematics through exploration, discussion, and reflection. The tasks in which students engage are both challenging and interesting, and students cannot quickly complete them by applying a known rule or procedure. Students must reason about and make sense of a situation and persevere when a pathway is not immediately evident. Students use a range of tools to support their thinking and collaborate with their peers to test and refine their ideas" (NCTM, 2017, p. 2).

In implementing integrated steM education, teachers are more likely to implement effective teaching practices in their other lessons as well by seeing the benefits of these practices.

Current standards support the implementation of integrated steM education at the high school level. In the U.S., the Next Generation Science Standards (2013) and the Common Core State Standards for Mathematical Practice (National Governors Association, 2010) provide science, engineering, and mathematical practices. These practices include mathematical modeling, integrating mathematics and computational thinking into science, planning and carrying out investigations of real world problems, analyzing and interpreting data, and designing solutions. A primary goal of integrated STEM education is to provide students with the opportunity to engage in real-world problem solving through hands-on experimentation, research, modeling, and design challenges (Mayes, Rittschof, Gallant, \& Martin, 2017). 
Integrated steM education has many benefits for students. It can develop students' mathematical understanding through different representations, students' interest in STEM fields and positive perceptions of STEM, and develop students' 21st century competencies that will help students in their current lives and any future career (Stohlmann, 2018). It can also help increase students' mathematical achievement which is important given that the number of students in remedial non-credit bearing mathematics courses has been increasing (Lee, 2012). Remedial mathematics classes can cause financial strain for students and delay or even prevent them from completing their degrees.

Integrated steM education is receiving more focus at the elementary and middle school level as well which will help students be more used to learning mathematics through this approach when they enter high school. In my prior work I detailed a vision for how middle school teachers can implement integrated steM education (Stohlmann, 2019a) and also have analyzed how elementary teachers implemented this approach after receiving professional development (Stohlmann, Maiorca, \& DeVaul, 2017). This prior work has demonstrated that teachers want further resources and classroom-tested curriculum for integrated steM education. Teachers have seen the benefits of this approach and want further support to implement it well.

Further work on integrated steM education can expand the curricular resources available for teachers. In studies done on integrated steM education at the high school level the mathematics has focused mainly on measurement, data analysis, functions, and creating equations (Stohlmann, 2018). Future research can look at further development of integrated steM curricula to expand the mathematical content that can be integrated. This curricula can then be researched to determine the impact of its implementation on various outcomes of high school students. High school mathematics teachers may need support for implementing open-ended problems so there is a need for professional development for teachers to be comfortable and effective with this approach.

Depending on a teacher's content knowledge of other subjects or the possibility to collaborate with teachers in other subjects, other subjects beyond the STEM subjects can be integrated as well. I integrated art with a study done with students and the Robot Art MEA. In this MEA students work in groups to determine the best method to communicate to one of the students how to draw a picture. The student who is the drawer pretends to be a robot and can only draw based on the directions that are given. Students learned the importance of clear programming directions for robotics and also more about the creativity of artists (Stohlmann, 2017c).

There are many benefits to integrated steM education for students. In this article I have shown ways in which these benefits can be realized with an integrated steM education approach with high school mathematics teachers. Integrated steM education is a dynamic and important topic to ensure that students are prepared to be successful in their current and future lives. With an increased emphasis on MEAs, mathematical modeling, and mathematics integrated with technology through game-based learning I believe it will be more likely for high school mathematics teachers to implement integrated steM education effectively.

\section{References}

ACT. (2017). STEM education in the U.S.: Where we are and what we can do. Retrieved from www.act.org/ stemcondition

Arleback, J., Doerr, H., \& O'Neil, A. (2013). A modeling perspective on interpreting rates of change in context. Mathematical Thinking and Learning, 15, 314-336.

Bray, A., \& Tangney, B. (2016). Enhancing student engagement through the affordances of mobile technology: A 21st century learning perspective on realistic mathematics education. Mathematics Education Research Journal, 28(1), 173-197.

Brown, J.P. \& Edwards, I. (2011). Modelling tasks: insight into mathematical understanding. In G. Kaiser, W. Blum, R. Ferri, \& G. Stillman (Eds.). Trends in teaching and learning of mathematical modelling. (pp.187-197). New York: Springer.

Busse, A. \& Kaiser, G. (2003). Context in application and modelling-an empirical approach. In Q. Ye, W. Blum, K. Houston, \& Q. Jiang (Eds.). Mathematical modelling in education and culture. (pp.3-15). Chichester, England: Horwood. 
Byun, J., \& Joung, E. (2018). Digital game-based learning for K-12 mathematics education: A meta-analysis. School Science and Mathematics, 118(3), 113-126.

Carr, R., Bennett, L., \& Strobel, J. (2012). Engineering in the K-12 STEM standards of the 50 U.S. states: An Analysis of presence and extent. Journal of Engineering Education, 101(3), 1-26.

Computer Science Teachers Association (2018). State of computer science education. Retrieved from https://code. org/files/2018_state_of_cs.pdf

Dude Perfect (2016). World record edition. Retrieved from https://www.youtube.com/ watch?v=gm2_6DX_0Bw\&t=402s

English, L. (2016). STEM education K-12: Perspectives on integration. International Journal of STEM Education, $3(3), 1-8$.

English, L. (2010). Modeling with complex data in the primary school. In R. Lesh, P. Galbraith, C. Haines, \& A. Hurford (Eds.), Modeling students' mathematical modeling competencies (pp. 287-299). New York, NY: Springer.

English, L. (2003). Reconciling theory, research, and practice: A models and modelling perspective. Educational Studies in Mathematics, 54(2/3), 225-248.

Fayer, S., Lacey, A., \& Watson, A. (2017). BLS spotlight on statistics: STEM occupations-past, present, and future. Washington, DC: U.S. Department of Labor, Bureau of Labor Statistics.

Fitzallen, N. (2015). STEM education: what does mathematics have to offer? In M. Marshman (Ed.), Mathematics education in the margins. Proceedings of the 38th annual conference of the Mathematics Education Research Group of Australasia (pp. 237-244). Sydney: MERGA

Foster, A., \& Shah, M. (2015). The play curricular activity reflection discussion model for game-based learning. Journal of Research on Technology in Education, 47(2), 71-88.

Hiebert, J., Carpenter, T., Fennema, E., Fuson, K., Wearne, D., Murray, H.,...Human, P. (1997). Making sense: Teaching and learning mathematics with understanding. Portsmouth, NH: Heinemann.

John, M., Bettye, S., Ezra, T., \& Robert, W. (2016). A formative evaluation of a southeast high school integrative science, technology, engineering, and mathematics (STEM) academy. Technology in Society, 45(1), 34-39.

Kim, Y.R., \& Tjoe, H. (2019). Mathematical modeling and multiple solution strategies: The case of sphero SPRK+. Paper presented at the 118th annual convention of the School Science and Mathematics Association. Salt Lake City, UT: SSMA.

Lee, J. (2012). College for all: Gaps between desirable and actual P-12 math achievement trajectory for college readiness. Educational Researcher, 41(2), 43-55.

Lesh, R., \& Doerr, H. (2003). Foundations of a model and modeling perspective on mathematics teaching, learning and problem solving. In R. Lesh \& H. Doerr (Eds.), Beyond constructivism: Models and modeling perspectives on mathematics problem solving, learning and teaching (pp. 3-38). Mahwah, NJ: Lawrence Erlbaum Associates.

Lesseig, K., Nelson, T., Slavit, D., \& Seidel, R. (2016). Supporting middle school teachers' implementation of STEM design challenges. School Science and Mathematics, 116(4), 177-188.

Maiorca, C., Stohlmann, M., \& Driessen, M. (2019). Getting to the bottom of the truth: STEM shortage or STEM surplus? In A. Sahin \& M. Mohr-Schroeder (Eds.). Myths and Truths: What Has Years of K-12 STEM Education Research Taught Us? (pp.22-35). Boston, MA: Brill.

Maiorca, C. (2016). A case study: Students' mathematics-related beliefs from integrated stem model-eliciting activities. Unpublished dissertation. Las Vegas, NV: University of Nevada, Las Vegas.

Mayes, R., Rittschof, K., Gallant, B, \& Martin, C. (2017). Real STEM: An interdisciplinary STEM program. Journal of Research in STEM Education, 3(1/2), 1-16.

National Academy of Sciences. (2014). STEM integration in K-12 education: Status, prospects and an agenda for research. Washington, DC: National Academies Press.

National Council of Teachers of Mathematics (NCTM). (2017). Taking action: Implementing effective teaching practices Grades 6-8. Reston, VA: National Council of Teachers of Mathematics.

National Council of Teachers of Mathematics (NCTM). (2014). Principles to actions: Ensuring mathematical success for all. Reston, VA: National Council of Teachers of Mathematics.

Next Generation Science Standards. (2013). Next generation science standards: For states, by states. Washington, D.C.: The National Academies Press.

National Governors Association Center for Best Practices, Council of Chief State School Officers (2010). Common core state standards for mathematics. Washington D.C.: NGAC, CCSSO.

National Science Board (2015). Revisiting the STEM workforce: A companion to science and engineering indicators 2014. Arlington, VA: National Science Foundation. 
Ohio 4H (2017). Rockets away! Launch simulator. Retrieved from http://www.ohio4h.org/statewide-programs/4h-science/science-alive-4-h-school-enrichment/rockets-away-launch-simulator.

Puentedura, R. (2006). Transformation, technology, and education. Retrieved from http://hippasus.com/resources/ tte/

Redmond-Sanogo, A., Angle, J., \& Davis, E. (2016). Kinks in the STEM pipeline: Tracking STEM graduation rates using science and mathematics performance. School Science and Mathematics, 116(7), 378-388.

Roehrig, G., Moore, T., Wang, H., \& Park, M. (2012). Is adding the E enough? Investigating the impact of K-12 engineering standards on the implementation of STEM integration. School Science and Mathematics, 112(1), 31-44.

Sdickson (2019). GeoGebra clinometer demonstration. Retrieved from https://www.geogebra.org/m/HN5hK2uU

Shaughnessy, M. (2013). By way of introduction: mathematics in a STEM context. Mathematics Teaching in the Middle school, 18(6), 324.

Smith, M., \& Stein, M. (2011). 5 practices for orchestrating productive mathematics discussions. Reston, VA: NCTM and Corwin.

Smith, M., Hughes, E., Engle, R., \& Stein, M. (2009). Orchestrating discussions. Mathematics Teaching in the Middle School, 14(9), 548-556.

Stohlmann, M. (2019a). Three modes of stem integration for middle school mathematics teachers. School Science and Mathematics, 119(5), 287-296.

Stohlmann, M. (2019b). "Math activities." Retrieved from https://www.micahstohlmann.com/math-activities. html

Stohlmann, M. (2019c). Integrated steM education through open-ended game based learning. Journal of Mathematics Education, 12(1), 16-30.

Stohlmann, M. (2018). A vision for future work to focus on the " $\mathrm{m}$ " in integrated STEM. School Science and Mathematics, 118(7), 310-319.

Stohlmann, M. (2017a). Desmos battleship. The Australian Mathematics Teacher, 73(2), 7-11.

Stohlmann, M. (2017b). Middle school students first experience with mathematical modeling. International Journal for Research in Mathematics Education, 7(1), 56-71.

Stohlmann, M. (2017c). Mathematical modeling with middle school students: The robot art model-eliciting activity. European Journal of STEM Education, 2(2), 1-13.

Stohlmann, M., Maiorca, C., \& DeVaul, L. (2017). Elementary teachers' engineering design activities from a state without engineering standards. Science Educator, 26(1), 48-59.

Stohlmann, M. \& Albarracin, L. (2016). What is known about elementary grades mathematical modelling. Education Research International, 2016, 1-9.

Stohlmann, M., Moore, T., \& Roehrig, G. (2012). Considerations for teaching integrated STEM education. Journal of Pre-College Engineering Education Research, 2(1), 28-34.

Surr, W., Loney, E., Goldston, C., Rasmussen, J., \& Anderson, K. (2016). From career pipeline to STEM literacy for all: Exploring evolving notions of STEM. Washington, DC: American Institutes for Research.

Vasquez, J., Sneider, C., \& Comer, M. (2013). STEM lesson essentials, grades 3-8: Integrating science, technology, engineering, and mathematics. Portsmouth, NH: Heinemann.

Wang, S., Chang, S., Hwang, G., \& Chen, P. (2018). A microworld-based roleplaying game development approach to engaging students in interactive, enjoyable, and effective mathematics learning. Interactive Learning Environments, 26(3), 411-423.

Wang, H., Moore, T., Roehrig, G., \& Park, M. S. (2011). STEM integration: Teacher perceptions and practice. Journal of Pre-College Engineering Education Research, 1(2), 1-13.

Zawojewski, J., Hjalmarson, M., Bowman, K., \& Lesh, R. (2008). A modeling perspective on learning and teaching in engineering education. In J. Zawojewski, H. Diefes-Dux, \& K. Bowman (Eds.), Models and modeling in engineering education (pp. 1-16). Rotterdam, The Netherlands: Sense Publishers. 